\title{
recillunds
}

Revista Cientifica Mundo de la Investigación y el Conocimiento

Julio Cesar Terrero Vásquez a ; Guisette Narcisa Fernández Álvarez b; Ignacio Guillermo Pacheco Méndez ${ }^{\text {c }}$ Liz Alejandra Mendoza León ${ }^{\mathrm{d}}$

Determinantes de salud y su influencia en los casos de dengue en el centro de salud tipo C, Buena Fe año 2018 -2019

Determinants of health and their influence in cases of dengue in the health center type C, Buena Fe year 2018-2019

Revista Científica Mundo de la Investigación y el Conocimiento. Vol. 3 núm. 4., diciembre, ISSN: 2588-073X, 2019, pp. 93-113

DOI: $\underline{10.26820 / \text { recimundo/3.(4).diciembre.2019.93-113 }}$

URL: http://recimundo.com/index.php/es/article/view/654

Código UNESCO: 3202 Epidemiología

Tipo de Investigación: Artículo de Revisión

(C) RECIMUNDO; Editorial Saberes del Conocimiento, 2019

Recibido: 15/09/2019

Aceptado: 23/11/2019

Publicado: 30/12/2019

Correspondencia: jterreroczs5@gmail.com

a. Licenciado en Enfermería; Maestrante de la Universidad Estatal de Milagro; Milagro, Ecuador; jterreroczs5@gmail.com

b. Médico; Investigador Independiente; Guayaquil, Ecuador; guissy_f@ @hotmail.com

c. Médico; Investigador Independiente; Guayaquil, Ecuador; ignaciopacheco92@gmail.com

d. Licenciada en Enfermería; Investigador Independiente; Guayaquil, Ecuador; lizita-92@ hotmail.com 


\section{Determinantes de salud y su influencia en los casos de dengue en el centro de salud tipo C, Buena Fe año 2018 -2019}

Vol. 3, núm. 4., (2019)

Julio Cesar Terrero Vásquez; Guisette Narcisa Fernández Álvarez; Ignacio Guillermo Pacheco Méndez; Liz Alejandra Mendoza León

\section{RESUMEN}

Objetivo: Identificar los determinantes de salud y su influencia en los casos de dengue en el centro de salud tipo C, Buena Fe año 2018-19. Metodología: La investigación determinante de salud y su influencia en los casos de dengue en el centro de salud tipo C, Buena Fe año 2018 es un estudio descriptivo porque se basará en la obtención de información a través de documentos y fuentes directas, las cuales se pueden comprobar, así también se explora una realidad actual, es de corte transversal porque se desarrollará en un tiempo determinado 2018-2019 y se examinarán las variaciones en las variables de estudio. Resultados: El 100\% de los pobladores del cantón Buena Fe acuden al centro de salud para ser atendidos lo que difiere de Solano que apenas el 41\% acuden a los subcentros y Sandoval 2018 que menciona que el 60\% de las familias se medican sin prescripción médica. Conclusiones: En base a los resultados obtenidos se acepta la hipótesis Los determinantes de salud influyen en los casos de dengue reportados en el Centro de Salud Tipo C de Buena Fé 2018-2019.

Palabras Claves: Aedes aegypti; Determinante de salud; Salud pública; Epidemiología. 


\section{Determinantes de salud y su influencia en los casos de dengue en el centro de}

salud tipo C, Buena Fe año 2018 -2019

Vol. 3, núm. 4., (2019)

Julio Cesar Terrero Vásquez; Guisette Narcisa Fernández Álvarez; Ignacio Guillermo Pacheco

Méndez; Liz Alejandra Mendoza León

\section{ABSTRACT}

Objective: To identify the determinants of health and their influence in cases of dengue in the health center type C, Buena Fe year 2018-19. Methodology: The determining health research and its influence on dengue cases in the type $\mathrm{C}$ health center, Buena Fe year 2018 is a descriptive study because it will be based on obtaining information through documents and direct sources, which will be You can check, so a current reality is also explored, it is cross-sectional because it will take place in a specific time 2018-2019 and the variations in the study variables will be examined. Results: $100 \%$ of the inhabitants of the Buena Fe canton go to the health center to be treated, which differs from Solano that only $41 \%$ go to the sub-centers and Sandoval 2018 that mentions that $60 \%$ of the families are medicated without prescription medical Conclusions: Based on the results obtained, the hypothesis is accepted. The health determinants influence the cases of dengue reported in the Type C Health Center of Good Faith 2018-2019.

Keywords: Aedes aegypti; Health determinant; Public health; Epidemiology. 


\section{Determinantes de salud y su influencia en los casos de dengue en el centro de salud tipo C, Buena Fe año 2018 -2019}

Vol. 3, núm. 4., (2019)

Julio Cesar Terrero Vásquez; Guisette Narcisa Fernández Álvarez; Ignacio Guillermo Pacheco Méndez; Liz Alejandra Mendoza León

\section{Introducción.}

La Organización Mundial de la Salud (OMS) propone la siguiente definición de salud "el estado de completo bienestar físico, mental y social y no solo la ausencia de enfermedad" se plantea diversas perspectivas epidemiológicas sobre la salud poblacional. La cual nos permite abordar aspectos sociales de la salud como son los determinantes sociales de la salud. (Raúl \& Roberto, 1996) (Kourí, 2011)

La determinación en salud es el proceso porque se producen las diversas formas de enfermar o morir de la población. Los determinantes sociales de la salud son las circunstancias en que las personas nacen, crecen, viven, trabajan y envejecen, y los sistemas establecidos para combatir las enfermedades que padecen. A su vez, estas circunstancias están configuradas por un conjunto más amplio de fuerzas económicas, sociales, normativas y políticas. Los determinantes están relacionados con aspectos tan variados como los biológicos, hereditarios, personales, familiares, sociales, ambientales, alimenticios, económicos, laborales, culturales, de valores, educativos, sanitarios y religiosos. (Álvarez Escobar, Torres Álvarez, Torres Álvarez, \& Semper González, 2018)

El cuadro actual de cómo se presenta dengue se ha visto influenciado por un modelo de causalidad de enfermedades infecciosas, donde el ambiente, el agente y el huésped están en una estrecha relación que finalmente llevan al desarrollo de la enfermedad. El ambiente es el factor más estudiado en la actualidad y es el responsable de la propagación de la mayoría de los casos de la enfermedad; "el aumento de la temperatura y el cambio climático que se está presentado en 


\section{Determinantes de salud y su influencia en los casos de dengue en el centro de}

salud tipo C, Buena Fe año 2018 -2019

Vol. 3, núm. 4., (2019)

Julio Cesar Terrero Vásquez; Guisette Narcisa Fernández Álvarez; Ignacio Guillermo Pacheco

Méndez; Liz Alejandra Mendoza León

el mundo se asocia con ascenso en la incidencia de los casos" (Luna Rodríguez, Gómez Peláez, \& Cando Caluña, 2018) (Parrales Pinargote, y otros, 2018)

Los casos de dengue que se presentan actualmente son un problema creciente para la salud pública en las áreas tropicales del mundo, es en la actualidad la enfermedad viral transmitida por mosquitos más importante que afecta a los seres humanos, producida por el virus del dengue, transmitida por la picadura de la hembra del mosquito Aedes aegypti. (Gómez Garcia, 2018) (Diéguez Fernández \& Cruz Pineda, 2011)

El presente estudio tiene como objetivo identificar los determinantes de salud y su influencia en los casos de dengue en el centro de salud tipo C, Buena Fe año 2018-19.

\section{Metodología.}

La investigación determinante de salud y su influencia en los casos de dengue en el centro de salud tipo C, Buena Fe año 2018 es un estudio descriptivo porque se basará en la obtención de información a través de documentos y fuentes directas, las cuales se pueden comprobar, así también se explora una realidad actual, es de corte transversal porque se desarrollará en un tiempo determinado 2018-2019 y se examinarán las variaciones en las variables de estudio.

El diseño de la investigación es no experimental de carácter cuantitativo por el tipo de información que se manejará. 


\section{Determinantes de salud y su influencia en los casos de dengue en el centro de salud tipo C, Buena Fe año 2018 -2019}

Vol. 3, núm. 4., (2019)

Julio Cesar Terrero Vásquez; Guisette Narcisa Fernández Álvarez; Ignacio Guillermo Pacheco Méndez; Liz Alejandra Mendoza León

Por la perspectiva general de la investigación, el investigador pretende conocer la realidad de los pacientes de dengue y establecer alternativas de cambio que permitan realizar conciencia en los ciudadanos del cantón Buena Fé.

\section{Métodos teóricos}

Se utilizó el método inductivo - deductivo ya que este método nos permitió conocer premisas particulares para llegar a una conclusión general

\section{Métodos empíricos}

Para la investigación se empleó como método empírico a la encuesta que se aplicó a los pacientes del Centro de Salud durante el año 2018-19

\section{Procesamiento estadístico de la información}

La información fue analizada en la hoja electrónica de Excel y se utilizó varios procedimientos estadísticos que permitieron la mejor interpretación de los resultados.

\section{Resultados.}

Datos generales

En relación a los datos generales en donde se indica cuanto tiempo vive en el sector existe un promedio de 33 años de vivir en el mismo lugar teniendo como valor mínimo 11 años y como valor máximo 60 años. El 90\% de los encuestados son oriundos del cantón Buena Fe y su zona de influencia, el 10\% tiene origen del cantón Santa Rosa provincia de El Oro. 


\section{Determinantes de salud y su influencia en los casos de dengue en el centro de}

salud tipo C, Buena Fe año 2018 -2019

Vol. 3, núm. 4., (2019)

Julio Cesar Terrero Vásquez; Guisette Narcisa Fernández Álvarez; Ignacio Guillermo Pacheco Méndez; Liz Alejandra Mendoza León

El $40 \%$ de los entrevistados jefes de familia son de sexo masculino con una edad promedio de 39,00 años y el 60\% son mujeres con una edad promedio de 38,67 años.

El núcleo familiar está conformado en un promedio de cuatro personas en donde el 50\% de los encuestados tiene tres integrantes de familia, un $10 \%$ registro ocho y dos integrantes respectivamente. En los núcleos familiares el $60 \%$ está conformado por infantes y $30 \%$ son adultos mayores.

El $100 \%$ de los encuestados sabe leer y escribir, de ellos el $50 \%$ ha completado la educación de nivel medio.

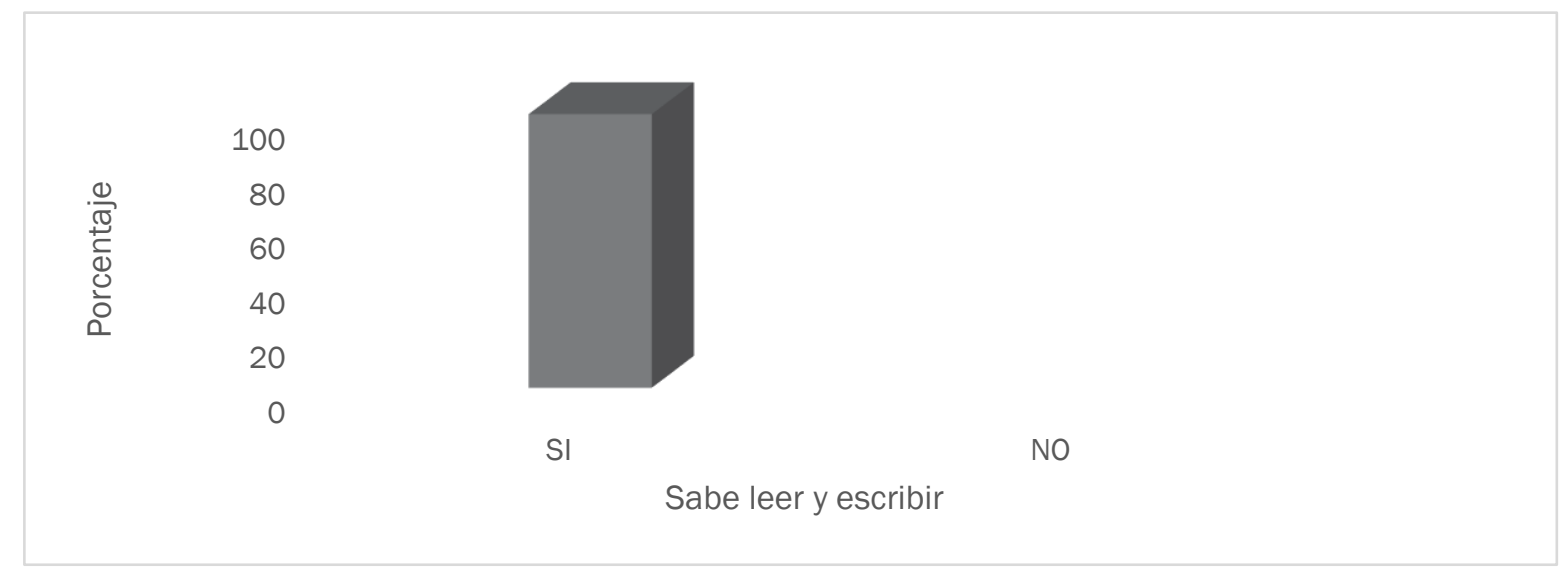

Figura 1. Saben leer y escribir los encuestados 
Determinantes de salud y su influencia en los casos de dengue en el centro de salud tipo C, Buena Fe año 2018 -2019

Vol. 3, núm. 4., (2019)

Julio Cesar Terrero Vásquez; Guisette Narcisa Fernández Álvarez; Ignacio Guillermo Pacheco Méndez; Liz Alejandra Mendoza León

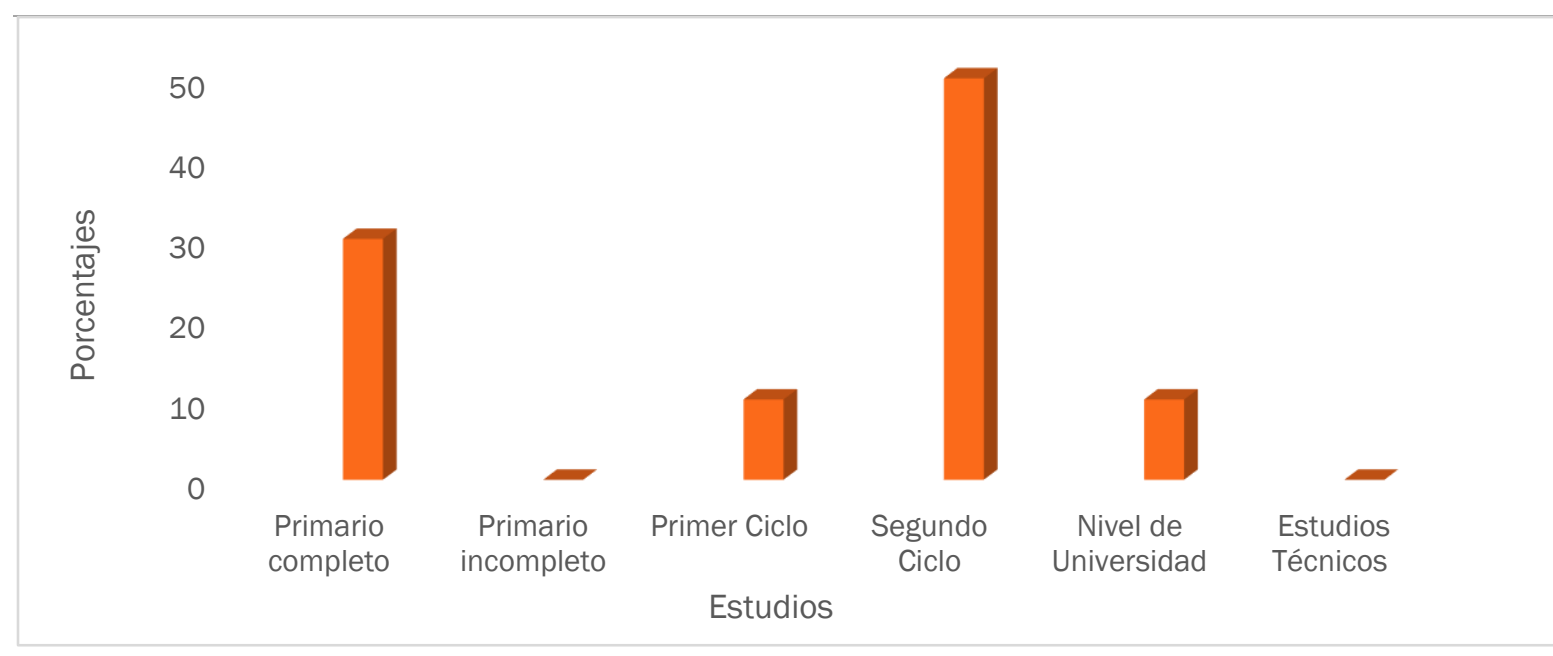

Figura 2. Nivel de estudios de los encuestados

Al preguntársele si tienen trabajo el 100\% reporto que si posee trabajo de los cuales el $40 \%$ se dedica a labores de agricultura y un $10 \%$ tiene negocio propio.

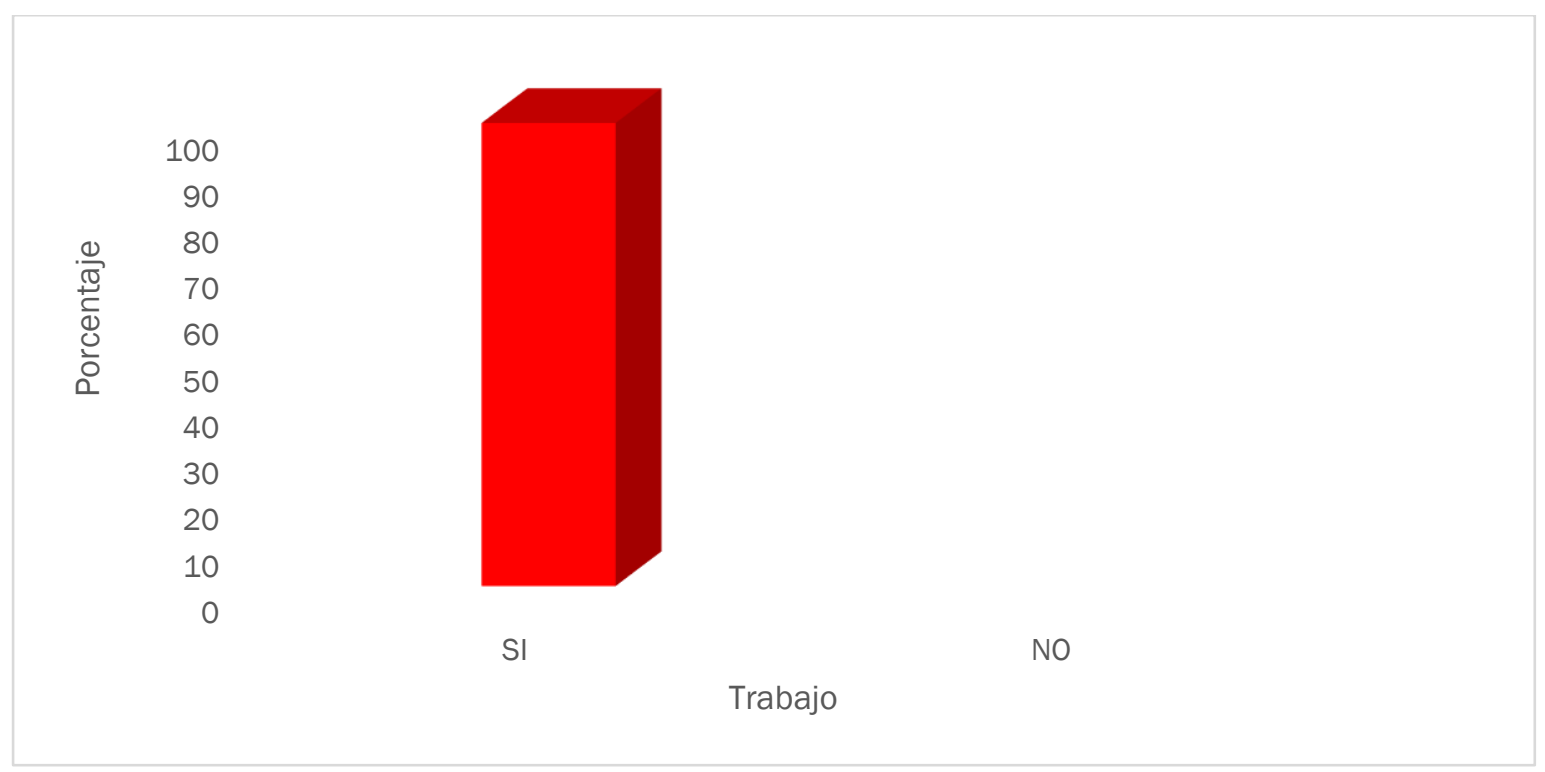

Figura 3. Tiene trabajo los encuestados 


\section{Determinantes de salud y su influencia en los casos de dengue en el centro de salud tipo C, Buena Fe año 2018 -2019}

Vol. 3, núm. 4., (2019)

Julio Cesar Terrero Vásquez; Guisette Narcisa Fernández Álvarez; Ignacio Guillermo Pacheco

Méndez; Liz Alejandra Mendoza León

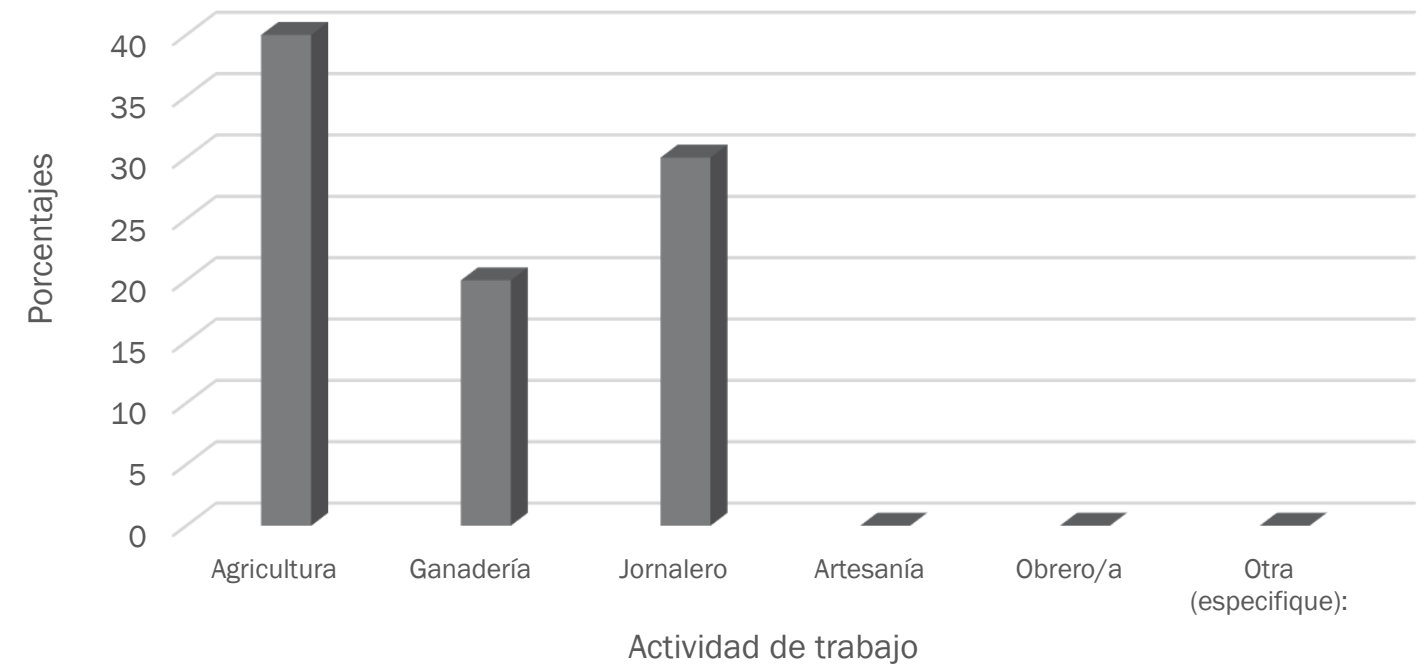

Figura 4. Actividad laboral de los encuestados

En lo concerniente a vivienda el $90 \%$ de los encuestados registra un techo de zinc, con paredes de bloque y piso de cemento, el $100 \%$ posee energía eléctrica, el $80 \%$ consume agua de pozo y $50 \%$ posee fosa séptica.
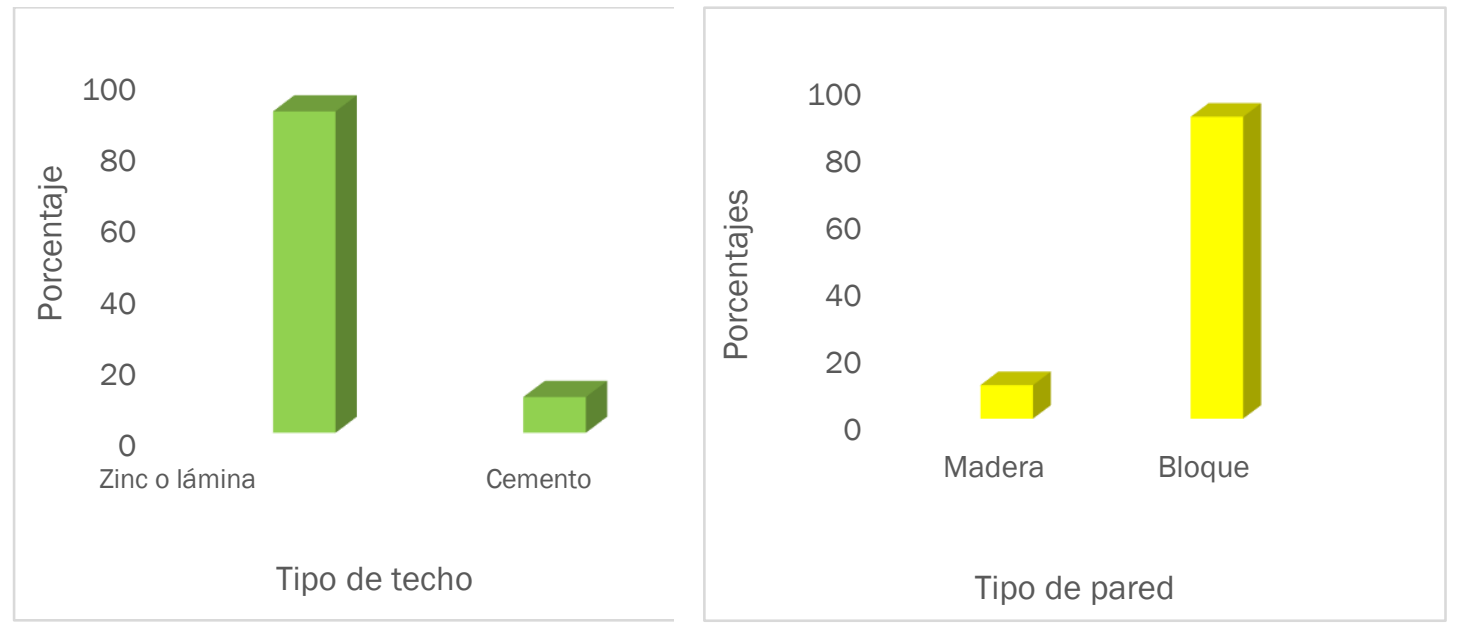
Determinantes de salud y su influencia en los casos de dengue en el centro de salud tipo C, Buena Fe año 2018 -2019

Vol. 3, núm. 4., (2019)

Julio Cesar Terrero Vásquez; Guisette Narcisa Fernández Álvarez; Ignacio Guillermo Pacheco Méndez; Liz Alejandra Mendoza León

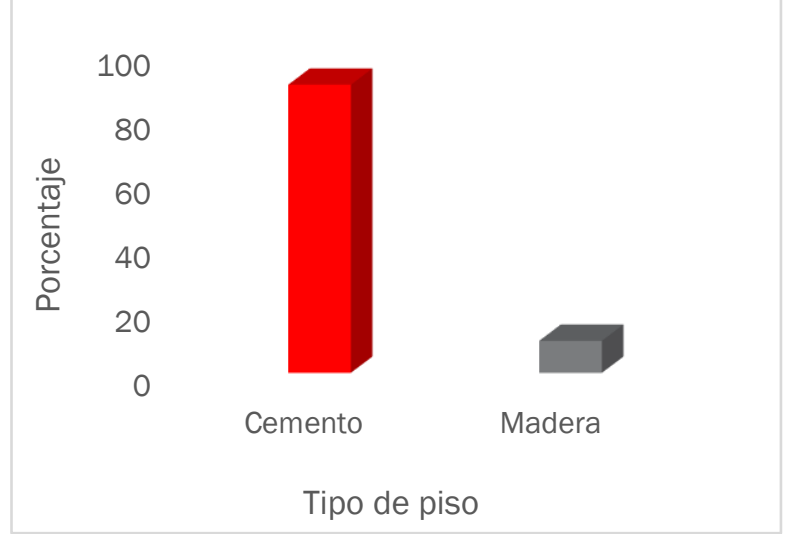

Figura 5. Vivienda de las personas encuestadas

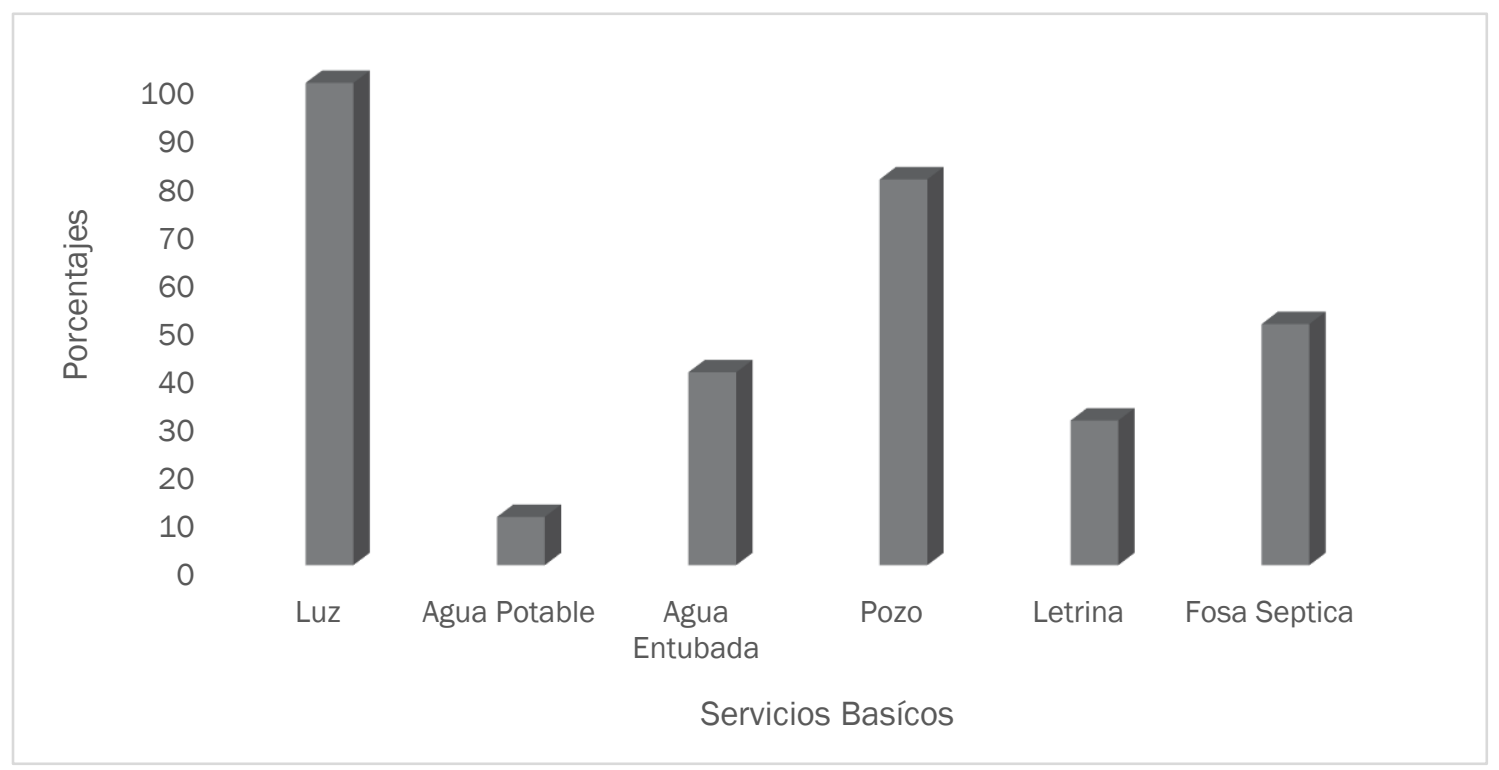

Figura 6. Servicios básicos de los encuestados

Se les pregunto cuántas veces al año viajan y su lugar de destino todos los encuestados mencionaron que salen de 1 a 2 veces al año a ciudades como Guayaquil y Quito, el viaje rutinario son a ciudades cercanas como Quevedo y Santo Domingo por situaciones de trabajo o de salud. 


\section{Determinantes de salud y su influencia en los casos de dengue en el centro de salud tipo C, Buena Fe año 2018 -2019}

Vol. 3, núm. 4., (2019)

Julio Cesar Terrero Vásquez; Guisette Narcisa Fernández Álvarez; Ignacio Guillermo Pacheco

Méndez; Liz Alejandra Mendoza León

Conocimiento de la enfermedad

Se les pregunto a los encuestados si alguna vez se han enfermado de dengue el $100 \%$ manifestó que sí, el 50\% de los encuestados indican que los que más han presentado la enfermedad son los hombres mayores, en las familias han vuelto a recaer al menos un familiar.
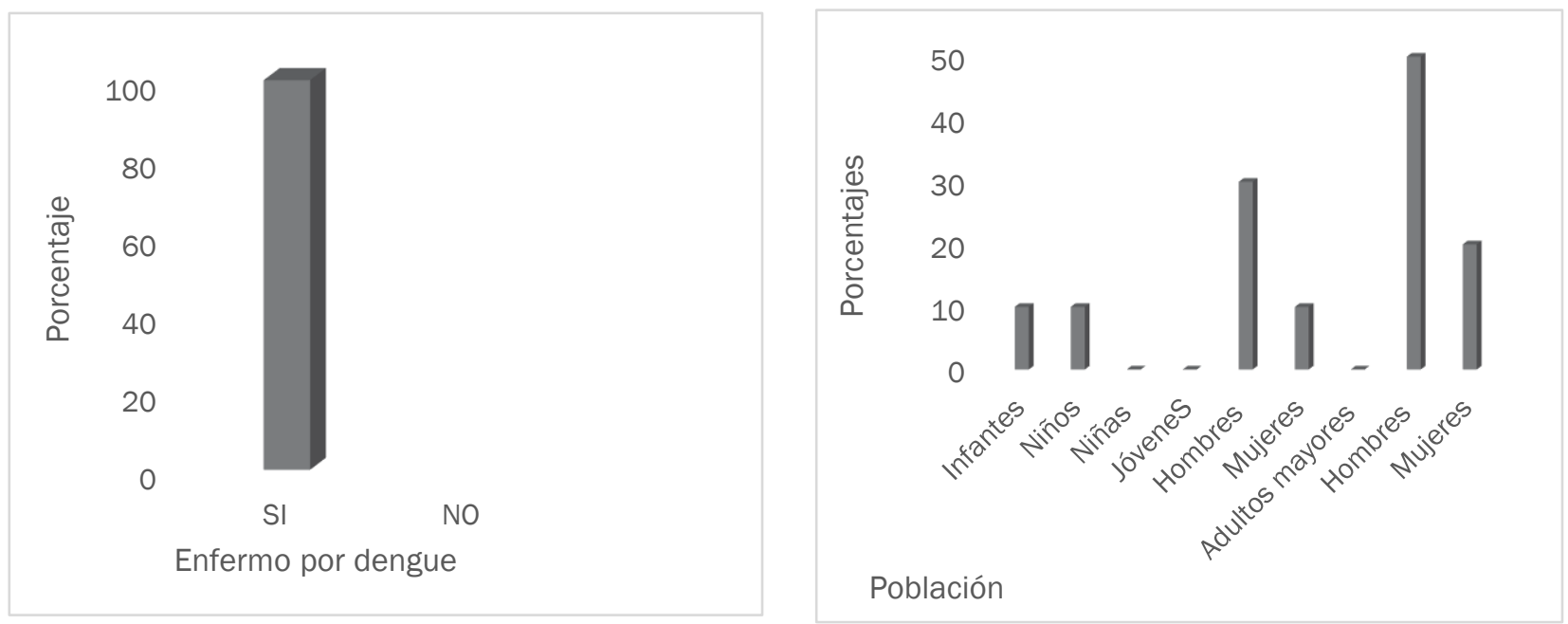

Figura 7. Enfermo por dengue y población afectada

El 90\% de las personas encuestadas consideran al dengue como un problema, el $40 \%$ indica que esto debe ser atendido por el Ministerio de Salud Pública. 
Determinantes de salud y su influencia en los casos de dengue en el centro de salud tipo C, Buena Fe año 2018 -2019

Vol. 3, núm. 4., (2019)

Julio Cesar Terrero Vásquez; Guisette Narcisa Fernández Álvarez; Ignacio Guillermo Pacheco Méndez; Liz Alejandra Mendoza León
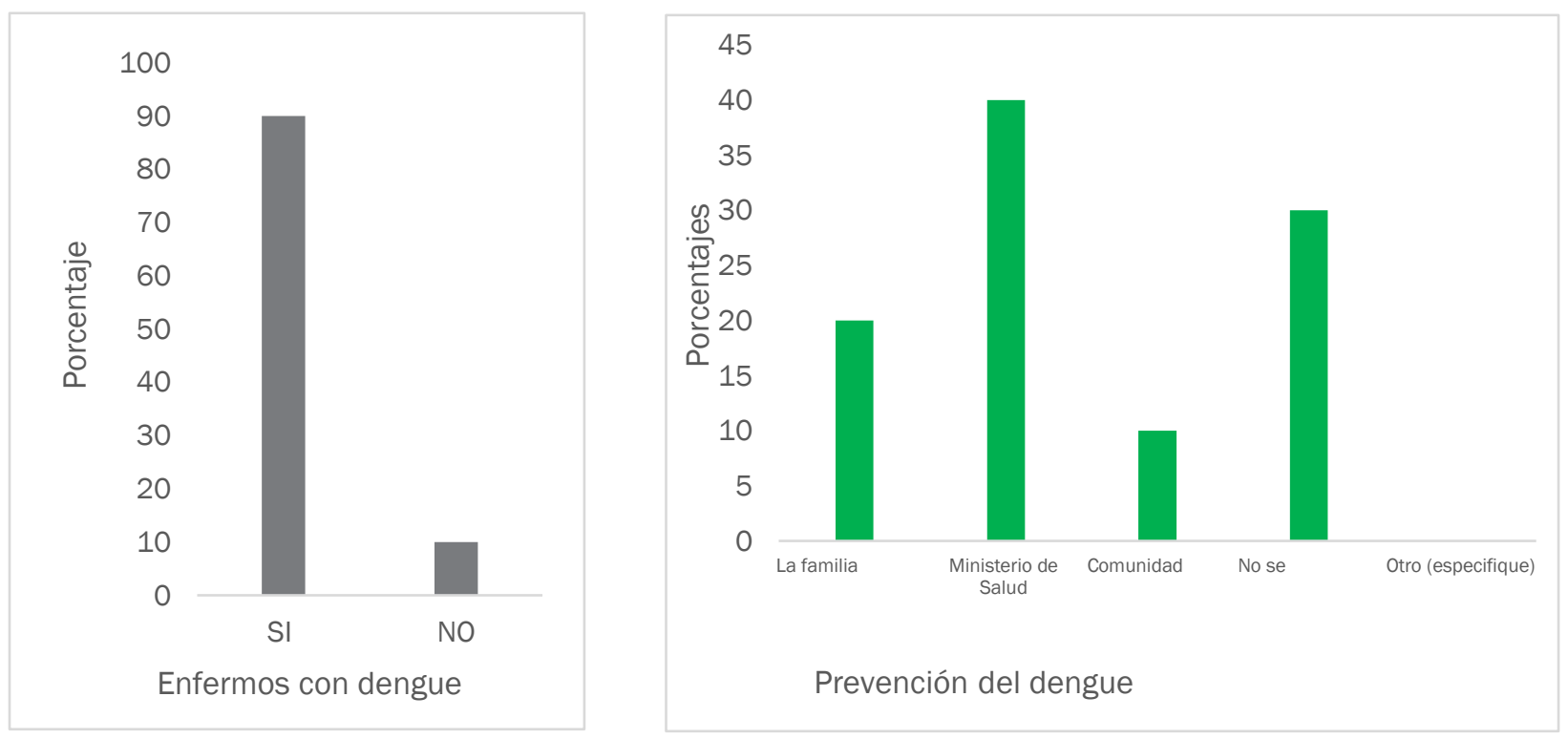

Figura 8. Personas con dengue y quien debe prevenir el dengue

El 70\% de las personas encuestadas respondieron que se enfermaron por la picadura de un mosquito, mientras un $20 \%$ considera que fue a través del agua.

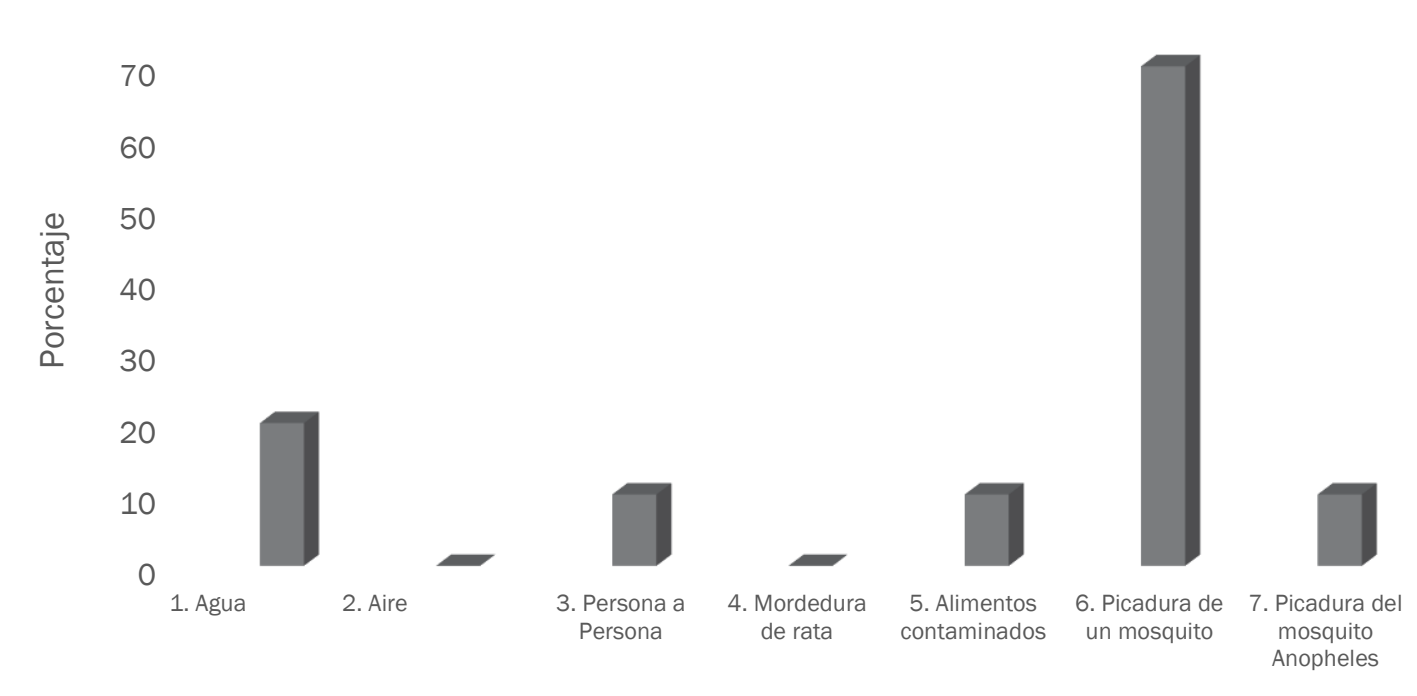

Como se enfermo porm dengue 


\section{Determinantes de salud y su influencia en los casos de dengue en el centro de salud tipo C, Buena Fe año 2018 -2019}

Vol. 3, núm. 4., (2019)

Julio Cesar Terrero Vásquez; Guisette Narcisa Fernández Álvarez; Ignacio Guillermo Pacheco

Méndez; Liz Alejandra Mendoza León

Figura 9. Como se enfermó de dengue

Al consultarles a las personas sobre los malestares que produce el dengue el $60 \%$ manifestaron que tienen fiebre alta y dolores en los músculos y huesos, el $40 \%$ añadió dolores de cabeza.

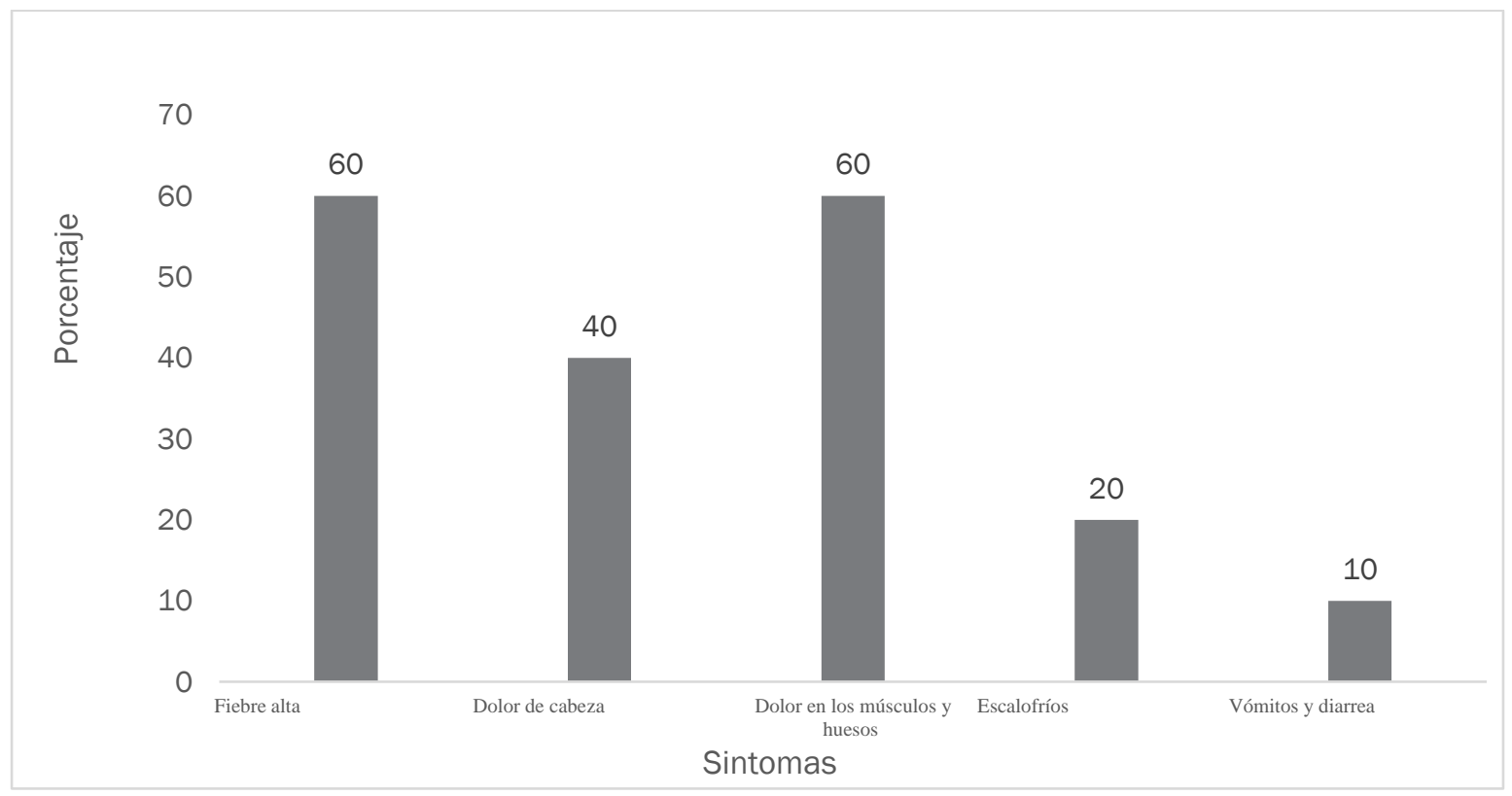

Figura 10. Síntoma de dengue en encuestados

En lo que respecta a como se cura el dengue el $100 \%$ de los encuestados indican que acuden al centro de salud y un $30 \%$ se auto medica tomando medicina tradicional antes de asistir al centro de salud.

Al preguntarle a los encuestados si conocían de personas que hayan muerto por dengue y que los funcionarios de salud hayan confirmado esa muerte, el 100\% respondió que no conocían. 
Determinantes de salud y su influencia en los casos de dengue en el centro de salud tipo C, Buena Fe año 2018 -2019

Vol. 3, núm. 4., (2019)

Julio Cesar Terrero Vásquez; Guisette Narcisa Fernández Álvarez; Ignacio Guillermo Pacheco Méndez; Liz Alejandra Mendoza León

Se preguntó qué tipo de examen se realizó para confirmar si tenía dengue y el $90 \%$ respondió haberse realizado un examen de sangre.

\section{Actitud}

Al preguntar a donde asisten cuando tienen dengue, el 100\% de los encuestados respondió que al Centro de Salud.

El 80\% de las personas encuestadas indicaron que se toman todos los medicamentos que le da el personal de salud.

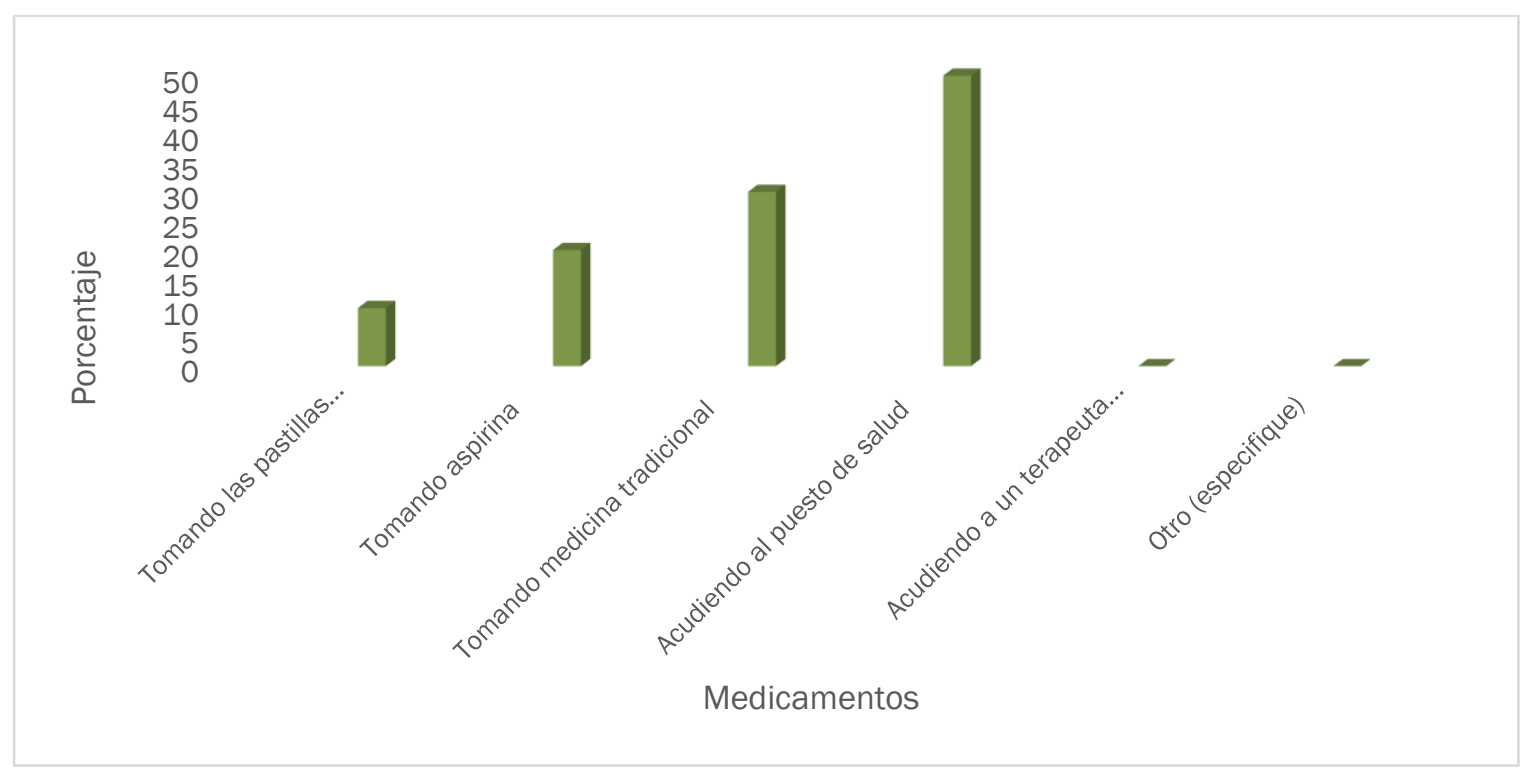

Figura 11. Medicamentos que consumen los encuestados

Al consultarles sobre si están de acuerdo con el rociado de insecticida en su casa el 70\% manifestó que están totalmente de acuerdo de esta medida sanitaria. 


\section{Determinantes de salud y su influencia en los casos de dengue en el centro de salud tipo C, Buena Fe año 2018 -2019}

Vol. 3, núm. 4., (2019)

Julio Cesar Terrero Vásquez; Guisette Narcisa Fernández Álvarez; Ignacio Guillermo Pacheco Méndez; Liz Alejandra Mendoza León

Al analizar la posibilidad que el personal de salud visite para atender los casos de dengue el $80 \%$ de las personas estuvieron de acuerdo.

Se preguntó si existen personas en la comunidad que curen en el dengue, el 50\% índico que no conocían y un $20 \%$ manifestaron que conocían que curanderos realizan esa labor.

Al preguntar a los encuestados como se cuidan para no enfermar por dengue, el $60 \%$ utiliza repelente, $40 \%$ utiliza mallas metálicas y mosquiteros y un $10 \%$ organizan jornadas de limpieza, rociado a las viviendas y protección personal.

\section{Prácticas}

En la pregunta sobre mantiene los canales y zanjas limpias alrededor de su casa, el 70\% indico que no realizan esta actividad.

Al preguntar sobre si rellenan los charcos o criaderos de mosquitos el $70 \%$ de los encuestados manifestaron que si lo hacían.

El 80\% de las personas usan mosquiteros o repelentes contra mosquitos para prevenir el contagio de dengue.

Percepción de las acciones del Ministerio de Salud

En relación a la pregunta si recibe una buena atención por parte de los funcionarios de salud, el $90 \%$ respondió que si reciben una buena atención. 


\section{Determinantes de salud y su influencia en los casos de dengue en el centro de salud tipo C, Buena Fe año 2018 -2019}

Vol. 3, núm. 4., (2019)

Julio Cesar Terrero Vásquez; Guisette Narcisa Fernández Álvarez; Ignacio Guillermo Pacheco Méndez; Liz Alejandra Mendoza León

De la misma forma se preguntó si el Ministerio de Salud realiza trabajos y jornadas de educación contra el dengue en su comunidad, el 90\% respondió que sí lo realizaban y un $80 \%$ indico que si emprenden jornadas de educación para difundir los riesgos de la enfermedad.

Al preguntar cada que tiempo reciben la visita de los funcionarios del Ministerio de Saludo un 30\% menciono que cada 60 días mientras otro 30\% manifestó que cada 90 días.

Acceso a la red de servicios de salud

En el ítem sobre el acceso a los servicios de salud se consultó a los encuestados si conocían sobre los servicios de salud que están disponibles en su comunidad, el $60 \%$ respondió que si conocían de los servicios de salud.

Se preguntó a los encuestados a que servicio de salud acude y el $60 \%$ indico que a los centros de salud, además se consultó si pueden viajar a las instalaciones a cualquier hora del día o la noche a lo que respondieron el $100 \%$ que si pueden trasladarse.

\section{Participación comunitaria}

Al realizar la investigación se preguntó si la familia y la comunidad realizan actividades para prevenir y controlar el dengue el $60 \%$ menciono que no realizan este tipo de actividades apenas un $20 \%$ realizan mingas. 


\section{Determinantes de salud y su influencia en los casos de dengue en el centro de salud tipo C, Buena Fe año 2018 -2019}

Vol. 3, núm. 4., (2019)

Julio Cesar Terrero Vásquez; Guisette Narcisa Fernández Álvarez; Ignacio Guillermo Pacheco

Méndez; Liz Alejandra Mendoza León

Se indagó si algún miembro de la familia forma parte de un grupo organizado dentro de la comunidad y el $70 \%$ manifestó que no pertenecen a ningún grupo solo un $20 \%$ pertenece a grupos religiosos.

Al preguntar cómo se ponen de acuerdo la comunidad con el personal de salud y las autoridades locales el $60 \%$ coincidieron en que no se ponen de acuerdo, un $30 \%$ menciono que programan las actividades.

Análisis comparativo, evolución, tendencia y perspectivas

La población encuestada en el centro de salud tipo $\mathrm{C}$ del cantón Buena $\mathrm{Fe}$ es mayoritariamente mujer en un 60\% lo que concuerda con Collazos, et al 2017 donde en los municipios de Anapoina y La Mesa reportan el 52,17\% y el 51,42\% del sexo femenino.

Dentro de los servicios básicos los encuestados reportaron energía eléctrica, consumo de agua de pozo y posee fosa séptica, lo que difiere a lo reportado por Collazos, et al 2017 quien menciona que en los municipios estudiados poseen del 95,10 al 98,40\% energía electrica, del 93,86 al 100\% agua potable y poseen en alto porcentaje alcantarillado y recolección de basura.

Al conocer el grado de instrucción que poseen los encuestados en el cantón Buena Fe el 50\% completo la educación de nivel medio valor similar al reportado por Solano 2014 quien indica que en el cantón Machala el 40,65\% y 32,50\% posee instrucción media y superior.

En relación al conocimiento de la enfermedad en el cantón Buena Fe el 100\% contesto que sí conocían por que habían adquirido la enfermedad, lo que coincide con Sandoval 2018 que 


\section{Determinantes de salud y su influencia en los casos de dengue en el centro de salud tipo C, Buena Fe año 2018 -2019}

Vol. 3, núm. 4., (2019)

Julio Cesar Terrero Vásquez; Guisette Narcisa Fernández Álvarez; Ignacio Guillermo Pacheco Méndez; Liz Alejandra Mendoza León

indica que en Esmeraldas el $80 \%$ de las familias tienen conocimientos básicos porque han reportado casos de dengue, Solano 2014 reporta en Machala un 60\% de conocimiento de la enfermedad, no así Fueltala 2017 menciona que en el cantón San Lorenzo el 60\% desconoce de la enfermedad.

Los encuestados en su gran mayoría indican que la causa del dengue es a través de la picadura de un mosquito lo que difiere de Fueltala 2017 quien menciona que en cantón San Lorenzo el $37 \%$ de las personas indica que se transmite por contacto con sangre.

Un alto porcentaje de encuestados reportaron como síntomas la fiebre alta y los dolores musculares y a los hueso lo que coinciden con Martínez 2008 quien reporta que los pacientes presentan formas febriles con dolores en el cuerpo, además esto difiere de lo encontrado por Fueltala 2017 quien manifiesta que el 51\% de las personas desconocen de los síntomas del dengue y colocan a la diarrea como el principal causante.

El $100 \%$ de los pobladores del cantón Buena Fe acuden al centro de salud para ser atendidos lo que difiere de Solano que apenas el 41\% acuden a los subcentros y Sandoval 2018 que menciona que el $60 \%$ de las familias se medican sin prescripción médica.

En la forma como se cuidan para no enfermar por dengue se mencionó que emplean repelentes, mallas metálicas y mosquiteros lo que concuerda con Sandoval 2018 que menciona el 96\% utiliza mosquiteros.

\section{Conclusiones.}




\section{Determinantes de salud y su influencia en los casos de dengue en el centro de salud tipo C, Buena Fe año 2018 -2019}

Vol. 3, núm. 4., (2019)

Julio Cesar Terrero Vásquez; Guisette Narcisa Fernández Álvarez; Ignacio Guillermo Pacheco

Méndez; Liz Alejandra Mendoza León

En relación a los determinantes conductuales las personas encuestadas presentan una actitud positiva ante la enfermedad del dengue ya que acuden al Centro de salud y consumen toda la medicación que prescribe el personal de salud, tienen una predisposición a que se los capacite para conocer sobre esta enfermedad, un bajo número de personas acuden a que los curanderos atiendan sus dolencias.

En el determinante ambiental las personas consumen agua de pozo, se evidencio que un alto número de encuestados no apoyan en la limpieza de lo que es canales y zanjas pero si rellenan lo que son charcos o criaderos de mosquitos.

Se pudo observar que las mujeres predominan como jefe de hogar y que los núcleos familiares tiene un promedio de cuatro integrantes existe un $60 \%$ de infantes y $30 \%$ de adultos mayores. El promedio de edad de las personas encuestadas es de 33 años con rangos desde 11 a 60 años.

Las personas encuestadas tienen un grado de instrucción de nivel medio las cuales trabajan en labores de agricultura y poseen negocios propios sin embargo un alto porcentaje menciono que no realizan actividades con la comunidad ni pertenecen a ningún grupo ya que nunca se ponen de acuerdo.

Debido a estos resultados se plantea desarrollar una Guía de estrategias para la práctica saludable frente al dengue con acciones de prevención, en donde se brindará charlas a la comunidad del cantón Buena Fe para mejorar la calidad de vida de sus habitantes. 


\section{Determinantes de salud y su influencia en los casos de dengue en el centro de salud tipo C, Buena Fe año 2018 -2019}

Vol. 3, núm. 4., (2019)

Julio Cesar Terrero Vásquez; Guisette Narcisa Fernández Álvarez; Ignacio Guillermo Pacheco Méndez; Liz Alejandra Mendoza León

En base a los resultados obtenidos se acepta la hipótesis Los determinantes de salud influyen en los casos de dengue reportados en el Centro de Salud Tipo C de Buena Fé 20182019.

\section{Bibliografía.}

Álvarez Escobar, M., Torres Álvarez, A., Torres Álvarez, A., \& Semper González, A. (2018). Dengue, chikungunya, Virus de Zika. Determinantes sociales. Revista Médica Electrónica, 40(1), 120-128.

Diéguez Fernández, L., \& Cruz Pineda, C. (2011). Aedes (St.) aegypti: relevancia entomoepidemiológica y estrategias para su control. Revista Archivo Médico de Camagüey, 15(3), 610-625.

Gómez Garcia, G. (2018). Aedes (Stegomyia) aegypti (Diptera: Culicidae) y su importancia en salud humana. Revista Cubana de Medicina Tropical, 70(1), 55-70.

Kourí, G. (2011). El dengue, un problema creciente de salud en las Américas. Revista Cubana de Salud Pública, 37(Supl), 616-618.

Luna Rodríguez, H., Gómez Peláez, G., \& Cando Caluña, W. (2018). Factores epidemiológicos asociados a dengue en pacientes adultos. RECIMUNDO, 2(2), 700-709.

Parrales Pinargote, L., Gavilánez Macías, E., Sornoza Pin, A., Amen Carrillo, S., Riofrio Pinargote, C., \& Jaime Hernández, N. (2018). Aspectos clínicos y epidemiológicos de los casos de zika en mujeres embarazadas del Cantón Jipijapa. RECIMUNDO, 2(2), 782-793.

Raúl, L., \& Roberto, B. (1996). Medicina teórica. Definición de la salud. Revista Medica Herediana, 7(3), 1-4. 
Determinantes de salud y su influencia en los casos de dengue en el centro de salud tipo C, Buena Fe año 2018 -2019 Vol. 3, núm. 4., (2019)

Julio Cesar Terrero Vásquez; Guisette Narcisa Fernández Álvarez; Ignacio Guillermo Pacheco Méndez; Liz Alejandra Mendoza León

$$
\text { (c) (i) () (2) }
$$

RECONOCIMIENTO-NOCOMERCIAL-COMPARTIRIGUAL

CC BY-NC-SA

ESTA LICENCIA PERMITE A OTROS ENTREMEZCLAR, AJUSTAR Y CONSTRUIR A PARTIR DE SU OBRA CON FINES NO COMERCIALES, SIEMPRE Y CUANDO LE RECONOZCAN LA AUTORÍA Y SUS NUEVAS CREACIONES ESTÉN BAJO UNA LICENCIA CON LOS MISMOS TÉRMINOS. 